\title{
Language and aging
}

\author{
Jonathan E. Peelle \\ Department of Otolaryngology, Washington University in Saint Louis, Saint Louis MO USA
}

To appear as:

Peelle JE (In press) Language and aging. In: The Oxford Handbook of Neurolinguistics (de Zubicaray and Schiller, eds). Oxford University Press.

Please address correspondence to:

Dr. Jonathan Peelle

Department of Otolaryngology

Washington University in Saint Louis

660 South Euclid, Box 8115

Saint Louis, MO 63110

email: jpeelle@wustl.edu 


\begin{abstract}
Language processing in older adulthood is a model of balance between preservation and decline: Despite widespread changes to physiological mechanisms supporting perception and cognition, older adults' language abilities are frequently well preserved. At the same time, the neural systems engaged to achieve this high level of success change, and individual differences in neural organization appear to differentiate between more and less successful performers. In this chapter, I review anatomical and cognitive changes that occur in aging and popular frameworks for age-related changes in brain function, followed by an examination of how these principles play out in the context of language comprehension and production.
\end{abstract}




\section{Introduction}

As we age, sensory and cognitive changes occur that create challenges for language processing. At the same time, we gain increased experience and expertise with language and may adopt more efficient processing strategies. These complementary facets of normal aging suggest that agerelated changes in language processing will be multifactorial.

Understanding language processing in older adulthood is important for both practical and theoretical reasons. Practically, a mechanistic understanding of how older brains' process language may help an increasingly aging population communicate. From a theoretical standpoint, predictions made regarding how sensory and cognitive factors jointly contribute to language processing should be borne out in older adults, who typically show more variability than their younger counterparts in both of these domains. That is, normal aging is just one example of neuroanatomical and behavioral variability that can be useful to test theoretically important issues in neurolinguistics. For example, to what degree is language processing modular (Fodor, 1983)? If older adults show different patterns of neural processing during language processing than young adults, what implications might this have for our understanding of cognitive organization? Healthy aging is therefore a useful model for studying behavioral success in the presence of changing biology, and the lessons learned have implications for a variety of demographic and clinical populations.

In this chapter, I present an overview of some main themes associated with cognitive aging, followed by specific examples of how older adults process language, focusing on neural mechanisms wherever possible (for comprehensive reviews of behavioral findings, see Kemper, 1992; Wingfield \& Stine-Morrow, 2000). Although I will focus on spoken language, many of the general principles also hold true for written and signed language.

\section{Cognitive aging}

Language processing in older adults can only be understood within a broader picture of agerelated cognitive change and mechanisms related to neural adjustment and compensation. I thus begin with a brief overview of the key points in the cognitive aging literature, many of which return more specifically in the context of language processing.

Age-related changes in brain structure and cognitive function

As we age, our brains get smaller and lighter: gyri widen and ventricles enlarge to a degree that is apparent to the naked eye on structural brain scans. It is not surprising then, to find significant reductions in gray matter volume and cortical thickness in older adulthood (Good et al., 2001; Raz et al., 1997; Raz, Gunning-Dixon, Head, Dupuis, \& Acker, 1998; Raz et al., 2005; Salat et al., 2004). Historically, age-related changes in gray matter have been discussed most often in the context of frontal and prefrontal cortex (Raz, et al., 1997), although there are age-related changes in nearly every region of the brain (Fjell et al., 2009; Peelle, Cusack, \& Henson, 2012). Changes in the composition of white matter are also common (Salat et al., 2005) and are typically measured using fractional anisotropy or other diffusion coefficients from diffusion-weighted imaging (see the Chapter by Catani \& Forkel, this volume). White matter changes are frequently interpreted as relating to demyelination and thus less efficient communication between brain regions, although caution should be used when interpreting diffusion-weighted measures (Jones, Knösche, \& Turner, 2013).

It is important to keep in mind methodological issues, such as changes in image contrast mechanisms associated with age (Salat et al., 2009) or the interpretation of regional change relative to global effects (Peelle, et al., 2012), which may affect these results. Nevertheless, there 
is clear evidence that our brains change as we age, even in the absence of neurodegenerative disease.

In addition to widespread neuroanatomical change, healthy aging is also associated with altered cognitive processing across a wide number of domains including working memory (Mitchell, Johnson, Raye, Mather, \& D'Esposito, 2000), attention and inhibitory control (Hasher, Stoltzfus, Zacks, \& Rypma, 1991), general processing speed constructs (Salthouse, 1996), and many others. Verbal knowledge is typically well preserved (and frequently increases with age, as evidenced by increasing vocabulary sizes; Verhaeghen, 2003), but nearly every other domain studied by cognitive aging researchers reveals significant age-related changes in accuracy, reaction time, or processing strategy (Hedden \& Gabrieli, 2004).

\section{Adaptive processing and compensation in older adulthood}

Given the concomitant neuroanatomical and cognitive changes that occur in normal aging, it would be surprising if older adults achieved a behavioral outcome with identical neural processes as young adults. As a first step, it can also be useful to examine differences in neural processing at the group level. Are there any consistent patterns that distinguish older adults' successful processing?

Since the early days of functional brain imaging, a frequent observation is that older adults tend to show less activity than young adults in the regions associated with that task in young adults, but increased activity in other regions (Grady, 2000). For example, Cabeza and colleagues (1997) performed a PET study of memory for pairs of words, and noted that older adults appeared to show reduced activity during encoding compared to the young adults (and increased bilateral activity during retrieval, discussed in more detail below). Reports of underactivation - that is, older adults showing reduced activity compared to young adults in what are assumed to be "core" processing areas for a task - have led to the suggestion that neural processing in older adults is less specialized than that of young adults (Park et al., 2004). The concurrent increases in activity viewed outside core regions are often viewed as compensatory, reflecting an older brain making up for lost processing efficiency by recruiting additional resources. Interpreting the older adults' "overactivation" as a beneficial adaptation has intuitive appeal, and is also supported by studies in which older adults' extra activity is correlated with behavioral accuracy. (However, such a correlation is not always found, meaning that compensation-related explanations for age-related differences in brain activity need to be viewed with caution.)

As hinted at above, a number of early studies examining age-related differences in neural processing used tasks in which young adults showed left-lateralized activation (that is, hemispheric asymmetry). When older adults performed the same task successfully, they frequently showed activity in the contralateral homologous region, and thus a lesser degree of hemispheric asymmetry. In Cabeza et al. (1997), for example, the authors found that during retrieval young adults showed right-lateralized activity in frontal cortex, whereas older adults showed bilateral activity in the same task. Although at the time it was uncommon to statistically assess the degree of lateralization in neuroimaging studies, qualitative results strongly suggested age differences in the degree of lateralized activity, at least for some tasks. Findings such as these led to the Hemispheric Asymmetry Reduction in OLDer adults (HAROLD) model (Cabeza, 2002), which proposed that reduction in hemispheric asymmetry is a key feature of neural processing in older adulthood, and is thus a guiding principle often used to consider age differences in activity. Additional frameworks proposing a key role for neural compensation in aging include the Compensation-Related Utilization of Neural Circuits Hypothesis (CRUNCH; Reuter-Lorenz \& Lustig, 2005) and Scaffolding Theory of Aging and Cognition (STAC; ReuterLorenz \& Park, 2014). CRUNCH and STAC also focus on the importance of compensatory 
activity, but are more agnostic about the specific type of activity to be expected (that is, there is less emphasis on reductions in lateralization). What these models have in common is that all propose increased activity is needed for older adults to maintain the same performance as young adults.

An important question concerns the nature of the compensatory "resources" older adults upregulate. What are these additional cognitive processes? One way to answer this question is to classify them as domain-preferential or domain-general. At a broad level, HAROLD-type activation may be considered as tending more towards the domain-preferential end of the spectrum, under the assumption that contralateral homologous regions frequently perform related functions. In contrast, another type of compensation would reflect upregulation of domaingeneral systems such as executive attention networks (Duncan, 2010; Power \& Petersen, 2013). These networks are considered domain-general because they can be dynamically engaged in the context of current task demands and goals, flexibly coding task-relevant information (Stokes et al., 2013; Woolgar, Hampshire, Thompson, \& Duncan, 2011). Examples of both are seen during language processing.

Keeping in mind the brain's ability to flexibly compensate for task-related challenge, successful aging can be seen as relying on the relationship between supply and demand of processing resources (Figure 1). Processing efficiency reflects the degree to which any individual has a neurocognitive capacity relevant for a given task; demand is determined by the current task requirements, which for language tasks might consist of the joint challenges of perceptual, sensory, and metalinguistic (i.e., thinking about the use of language) processing. If an individual's neural resources are sufficient to meet the demand, performance will be high. If not, performance will begin to deteriorate. Poor performance thus results from a mismatch between cognitive supply and demand. (In some sense, this can be thought of equally as reflecting too great of a behavioral challenge or too few neural resources, although the degree to which this distinction matters is an open question.)

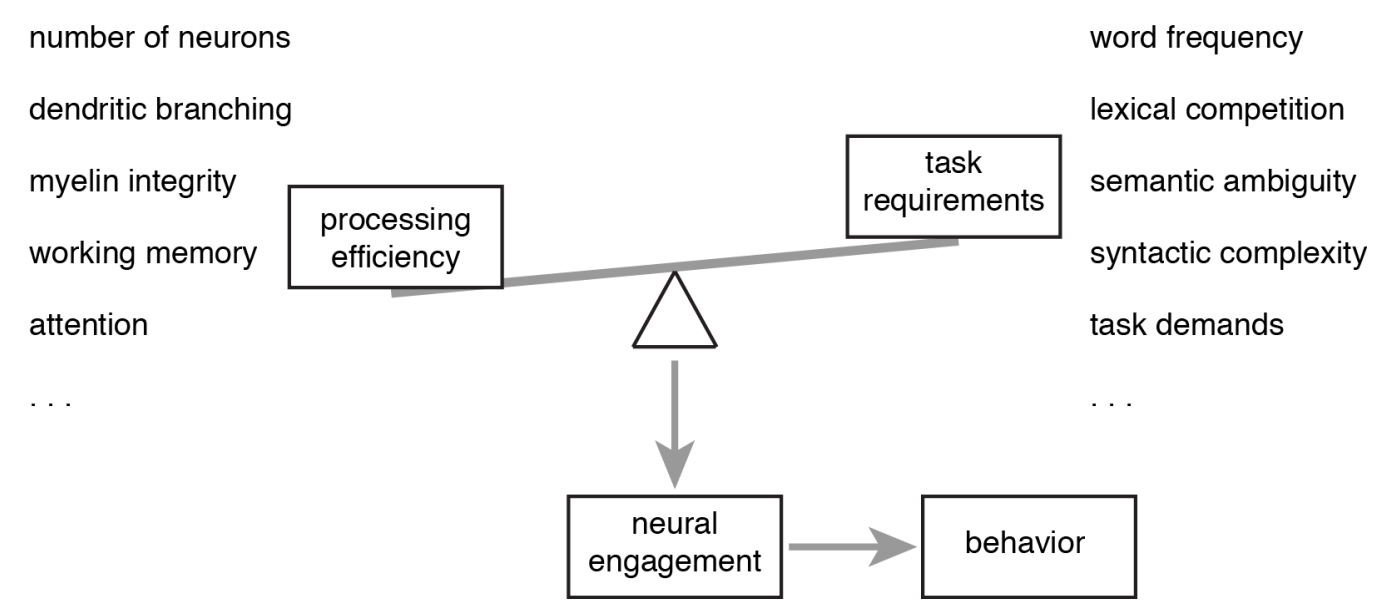

Figure 1. Schematic framework within which to consider the neural networks supporting language processing. The neural systems engaged and degree of behavioral success reflect a complex balance between the specific task requirements (including the level of linguistic processing required) and the level of cognitive resources listeners have available (which is tied to underlying neurophysiology). 
Finally, as with structural MRI data, it is important to consider methodological concerns that might lead to age-related changes in functional measures that are unrelated to cognitive processing. These include differences in the shape or timing of the hemodynamic response (D'Esposito, Zarahn, Aguirre, \& Rypma, 1999), neurovascular coupling (Tsvetanov et al., 2015), and movement within the scanner that may affect estimates of activity or network connectivity (Power, Barnes, Snyder, Schlaggar, \& Petersen, 2012). Increased variability in the timing of neural responses can also significantly impact group-averaged event-related potentials (ERPs).

Having thus briefly set the stage with a general framework for successful performance in normal aging, I now turn to reviewing comprehension and production of language in older adulthood as specific applications of these general principles.

\section{Language comprehension in normal aging}

Most neuroantomically-constrained models of spoken language comprehension have been formulated based on known anatomical connectivity, behavioral data from stroke patients, and functional brain imaging in healthy (typically young) adults. There is good general agreement on the importance of bilateral temporal cortex for auditory and single-word processing, extending into left lateral temporal cortex and inferior frontal gyrus (IFG) in the context of sentence-level material (Hickok \& Poeppel, 2007; see Chapters by Poeppel, Cogan, Davidesco \& Flinker, and Bornkessel-Schlesewsky \& Schlesewsky, this volume; Peelle, Johnsrude, \& Davis, 2010; Rauschecker \& Scott, 2009). However, much less is known regarding how these networks change in the context of healthy aging. In the sections below, I discuss patterns of neural processing for language in older adults relative to those seen in young adults, some illustrations of which are shown in Figure 2. 
A) Words in noise

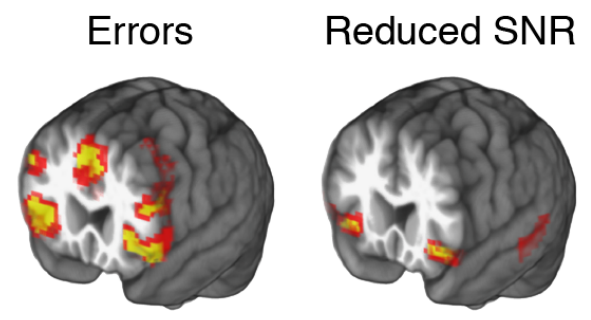

B) Anomolous sentences

Young adults
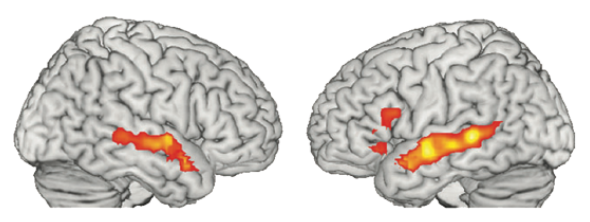

Older adults
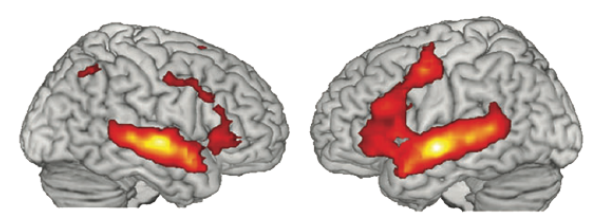

\section{C) Syntactic complexity}

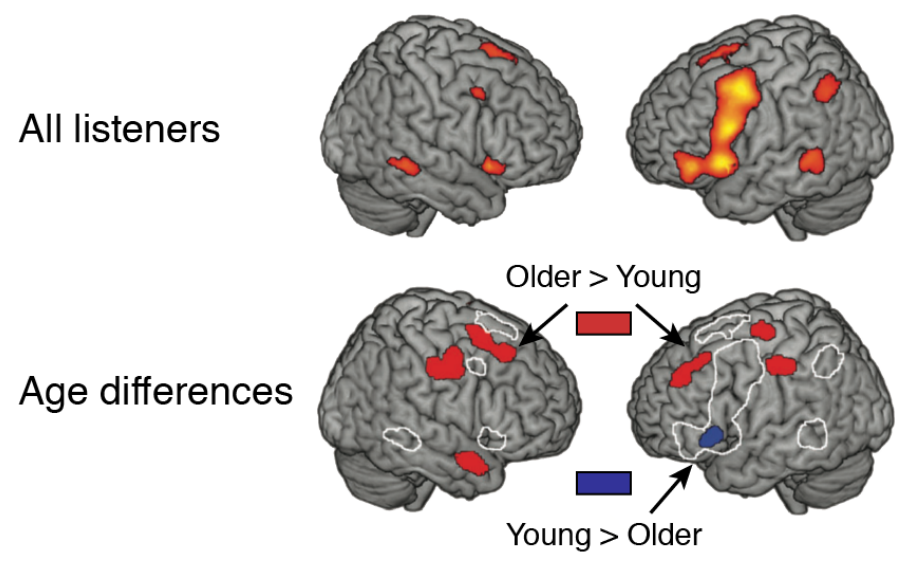

Figure 2. (A) Increased activity in the cingulo-opercular network during spoken word processing in response to both errors and poorer signal-to-noise ratio (SNR) (Vaden Jr., et al., 2015). (B) Activity for spoken sentences with anomalous prose in young and older adults during a target word monitoring task (Tyler, et al., 2010). Older adults show increased activity in right frontal cortex to support sentence comprehension. (C) Regions showing differential activation for spoken sentences with subject-relative vs. subject-relative embedded clauses (Peelle, Troiani, et al., 2010). Older adults show less activity in left inferior frontal gyrus, but greater activity in regions of prefrontal cortex outside the common syntax network. Used by permission of Oxford University Press. 
Word perception

Contemporary theories of spoken word perception frequently operate within a lexical competition framework in which listeners must correctly identify a target word by inhibiting (or not selecting) similar-sounding items in the lexicon (Gagnepain, Henson, \& Davis, 2012; Luce \& Pisoni, 1998; Marslen-Wilson \& Tyler, 1980; Norris \& McQueen, 2008). Behaviorally, older adults have more difficulty recognizing spoken words, particularly in noise (Dubno, Dirks, \& Morgan, 1984; Pichora-Fuller, Schneider, \& Daneman, 1995), and studies show that older adults' spoken word processing is affected by both lexical and cognitive factors (Humes, Kidd, \& Lentz, 2013; Lash, Rogers, Zoller, \& Wingfield, 2013; Sommers \& Danielson, 1999). What are the neural processes engaged?

Shafto and colleagues (2012) presented young and older adults with spoken words and nonwords that varied in both cohort competition (Marslen-Wilson, 1987) and imageability, along with a complex acoustic baseline. Young adults show increased activity in IFG as a function of increased lexical competition and selection demands (Zhuang, Tyler, Randall, Stamatakis, \& Marslen-Wilson, 2014). In contrast, older adults appear to be less sensitive to competition and selection manipulations, although potentially more sensitive to imageability effects (Shafto, et al., 2012). Research with visual word identification also suggests some age differences in processing that may dissociate lexical and sublexical components (Whiting et al., 2003). These studies suggest that even at the single word level, well-known lexical properties may be processed differently in older adults compared to young adults.

Functional MRI studies of spoken word perception in older adults also implicate executive attention systems in speech perception when noise is present. Eckert and colleagues (2008) presented listeners with single spoken words that were low-pass filtered (to mimic the effects of high-frequency hearing loss); intelligibility varied as a function of the cutoff frequency. Overall intelligibility across age groups was equated using broadband noise. On each trial, listeners repeated the presented word back if possible, providing a trial-by-trial measure of recognition accuracy. For correct trials, older adults showed different patterns of activation compared to young adults, with increased activity in middle frontal gyrus, anterior cingulate, and visual cortex. These results suggest that in challenging listening situations, older adults rely to a greater degree on executive attention mechanisms (middle frontal gyrus and anterior cingulate) than do young adults, even when they are successful.

It is difficult to talk about the neural systems contributing to speech perception in adverse listening conditions without discussing the cingulo-opercular network. The cingulo-opercular network is part of the multiple-demand network, comprising the dorsal anterior cingulate and bilateral frontal operculum (or anterior insula, depending on the characterization) (Dosenbach, Fair, Cohen, Schlaggar, \& Petersen, 2008; Duncan, 2010; Power \& Petersen, 2013). Across a variety of tasks the cingulo-opercular network shows elevated responses for sustained attention and error trials (Neta et al., 2015). In spoken word processing, elevated cingulo-opercular activity is seen in speech comprehension tasks when the acoustic signal is degraded enough to result in reduced intelligibility (and thus behavioral errors), including in older adults (Eckert et al., 2009). Further evidence for the functional role of the cingulo-opercular network in language processing comes from studies examining whether activity following one trial can predict accuracy on the next. Vaden and colleagues (2015) examined this issue using general linear mixed model analysis to predict the accuracy of participants' single word recognition in multitalker babble. The authors found, first, that activity in older adults' cingulo-opercular network predicted their accuracy on a subsequent trial, and, second, that the level of cinguloopercular modulation was lower for older adults than for young adults (Vaden Jr. et al., 2013). 
These findings implicate cognitive control mechanisms supported by the cingulo-opercular network in single word perception.

Of course, regions beyond the cingulo-opercular network have also been implicated in older adults' word perception. Kuchinsky and colleagues (2012) also presented single words that had been bandpass filtered to different levels in order to manipulate intelligibility. As expected, word perception was associated with bilateral temporal cortex activity. Both increasing age, and decreasing word intelligibility, were associated with more activation in occipital cortex. Interestingly, occipital cortex was functionally connected to left temporal cortex (including middle temporal cortex, superior temporal gyrus, and Heschl's gyrus), suggesting it may have a relationship to task-relevant processing. These results suggest that cross-modal attention to speech cues may be impacted by age, as well as the quality of the auditory stimuli being presented.

In summary, single word processing in older adults appears to be supported broadly by similar systems to those used by young adults - namely, bilateral temporal cortex. However, differences have been reported with respect to psycholinguistic and attentional factors. Published studies to date suggest that older adults use a more extensive set of brain regions when processing single words, and suggest a complex interaction between brain structure, brain function, and behavior (Bilodeau-Mercure, Lortie, Sato, Guitton, \& Tremblay, 2015). A further point is that the acoustic clarity of items (including age-related changes in hearing sensitivity) appears to have a significant impact; I return to the important issue of perceptual challenge in more detail below.

\section{Sentence comprehension}

In addition to the phonological, lexical, and semantic computations involved in single word perception, sentences require additional processes related to correctly parsing the syntax of an utterance, and frequently contain words (such as pronouns or ambiguous words) that require context to interpret (Rodd, Johnsrude, \& Davis, 2012). These added complexities mean that spoken sentences generally rely on a broader network of brain regions than required for single words, including more extensive regions of bilateral temporal cortex and left IFG (Peelle, 2012).

A productive line of research on semantic processing has used EEG (see Chapter by Leckey \& Federmeier, this volume) to investigate time-locked activity to words occurring with different levels of preceding predictability. These studies therefore assess the ability of listeners to make use of semantic context during online sentence comprehension. Federmeier and Kutas (2005) presented young and older adults with written sentences in which the final word was highly predictable (e.g., No one at the reunion recognized Dan because he had grown a beard) or not very predictable (e.g., At the children's park next to the beach she saw a man with a beard). Young adults showed a pronounced difference in time-locked response between strongly- and weakly-constrained sentences, an expected N400 response (Kutas \& Hillyard, 1984). In contrast, older adults as a group showed less difference between the strongly- and weakly-constrained sentence types, suggesting that older adults may be less able to use contextual constraints during online sentence processing (Wlotko, Federmeier, \& Kutas, 2012). Later studies suggest that individual differences exist, with some older adults showing patterns that are more similar to those seen in young adults (Federmeier, Kutas, \& Schul, 2010). (These online EEG measures can be contrasted with behavioral measures that frequently show older adults showing greater reliance on context compared to young adults Dubno, Ahlstrom, \& Horwitz, 2000; Pichora-Fuller, et al., 1995; Wingfield, Aberdeen, \& Stine, 1991.)

Behaviorally, there is considerable evidence that older adults have difficulty processing syntactically complex sentences, including reduced use of grammatical complexity in production (Kemper, Greiner, Marquis, Prenovost, \& Mitzner, 2001; Kemper, Marquis, \& Thompson, 
2001), and differentially longer response times on comprehension tasks (Kemtes \& Kemper, 1997; Waters \& Caplan, 2001; Wingfield, Peelle, \& Grossman, 2003). Functional neuroimaging studies of age-related changes in sentence processing have reported at least two patterns of results.

In the first fMRI study, young and older adults were presented with short spoken sentences that contained either a subject-relative or object-relative center-embedded clause, making a keypress response to indicate the gender of the character performing the action (Peelle, Troiani, Wingfield, \& Grossman, 2010). For example, when hearing the sentence "Brothers that sisters assist are happy", participants would press a button to indicate that a female is performing the action (in this case, assisting). Older adults' accuracy was generally high on this task, consistent with a high level of successful comprehension. Both young and older listeners showed increased activity for the more complex object-relative sentences compared to subject-relative sentences. However, older adults showed less activity than the young adults in left ventral IFG, and increased activity in regions of dorsolateral prefrontal cortex and premotor cortex. Thus, to maintain high levels of sentence comprehension accuracy, older adults showed additional frontal recruitment.

Tyler and colleagues (2010) took a slightly different approach, having young and older participants perform a word monitoring task in sentences with normal prose, anomalous prose, and random word lists. The anomalous prose sentences were grammatically correct but did not convey a coherent meaning (e.g., "Stephen didn't catch himself very much. Her tooth was driven because he had a weak nail and she couldn't heat anyone properly."). The authors focused on regions showing increased activation for the anomalous prose condition compared to an acoustic baseline. Overall, as in Peelle et al. (2010), young and older adults relied on a largely similar network of regions (bilateral superior temporal gyrus and left IFG), although there was some indication that older adults showed increased activity in the right IFG. Most interesting, however, was a second analysis in which they looked at whether individual differences in gray matter in left IFG were related to the activation they saw in right IFG. Indeed, older listeners with reduced gray matter in left IFG and left middle temporal gyrus showed increased activity in right hemisphere homologues of these regions, producing a more bilateral pattern of activation in the older adults relative to young adults. Importantly, these findings suggest that individual differences in cortical integrity may help explain patterns of compensatory activity (as suggested by Figure 1).

A critical distinction to consider is whether processing is interpretive (occurring when the meaning of the sentence is being calculated) or post-interpretive (occurring after the meaning has been determined). A classic example of post-interpretive processing would be making a metalinguistic decision about a sentence, such as whether it is grammatically appropriate. These two stages may also be thought of as "online" (interpretive) vs. "offline" (post-interpretive) processing. The online-offline distinction may be particularly important in the context of experimental paradigms requiring a response (such as a button press, or recall) from participants, as this adds task-related cognitive demands which are likely separate from those required for comprehension (Davis, Zhuang, Wright, \& Tyler, 2014). It has been argued that older adults show similar online processing to young adults, but differences in offline processing (Caplan \& Waters, 1999; Waters \& Caplan, 2001). Alternatively, others have suggested that domain-general cognitive systems are required for interpreting challenging sentences, and not simply for metalinguistic decisions (Wingfield \& Grossman, 2006). Although it seems likely that both levels of processing are affecting during aging, the issue remains a topic of debate.

In summary, age differences in neural activity during sentence comprehension are routinely observed, particularly when semantic or syntactic challenges are explicitly introduced. 
However, disagreement persists regarding the degree to which these reflect online vs. offline processing demands, and whether they reflect domain-preferential or domain-general cognitive processes.

\section{Perceptual challenge and effortful listening}

Normal aging is associated with changes at nearly every level of the auditory system (Peelle \& Wingfield, 2016). Loss of hearing sensitivity is common in normal aging, particularly in higher frequencies (Morrell, Gordon-Salant, Pearson, Brant, \& Fozard, 1996). Other age-related changes in hearing include broadening frequency filters and reduced accuracy of temporal processing (Humes, Kewley-Port, Fogerty, \& Kinney, 2010; Schneider, 1997). Thus, understanding the processes supporting speech comprehension in older adults requires considering the effects of reduced auditory sensitivity.

Subjectively, hearing impairment is frequently associated with "effortful" listening (Pichora-Fuller et al., 2016). There is growing evidence that listening effort reflects, in part, additional cognitive processing that is required to make sense of degraded speech (Rönnberg et al., 2013; Wingfield, Tun, \& McCoy, 2005). The role of acoustic challenge on word perception is seen in cases where adding external noise decreases intelligibility in proportion to how many phonological neighbors a word has - that is, the more lexical competitors, the more difficult accurate perception becomes (Luce \& Pisoni, 1998), particularly for older adults (Sommers, 1996). Hearing loss similarly affects perception, with hearing impaired listeners requiring more acoustic information before identifying a word (Lash, et al., 2013).

Some of the most compelling behavioral evidence for the cognitive consequences of acoustic challenge comes from episodic memory paradigms in which listeners are asked to recall lists of unrelated words or digits, some of which are presented in noise. In these situations, memory is worse not only for the item presented in noise, but also for previous items which were not degraded (Piquado, Cousins, Wingfield, \& Miller, 2010; Rabbitt, 1968). The disruption of memory encoding is consistent with increased working memory resources being needed to comprehend noisy speech (Cousins, Dar, Wingfield, \& Miller, 2014; Miller \& Wingfield, 2010). Memory effects for spoken language are also seen in participants with age-related hearing loss (McCoy et al., 2005; Rabbitt, 1991), although depending on the specific task individual differences in hearing ability may not correlate with memory measures (Ward, Rogers, Van Engen, \& Peelle, 2016).

Neuroimaging evidence for effects of perceptual challenge in older adults has been discussed above for words that have been acoustically degraded through background noise or low-pass filtering (Eckert, et al., 2009; Eckert, et al., 2008; Vaden Jr., et al., 2015). Additional support is emerging in the context of spoken sentences. Erb and Obleser (2013) presented spoken sentences to young and older adults; the sentences were normal or acoustically degraded using noise vocoding with 4 channels. Noise vocoding reduces the spectral detail in the speech, but leaves the temporal amplitude envelope preserved (Shannon, Zeng, Kamath, Wygonski, \& Ekelid, 1995); speech vocoded with 4 channels is typically somewhat intelligible. The authors found that older adults showed increased activation in dorsal anterior cingulate cortex in response to degraded speech compared to the younger adults. Furthermore, individual differences in activity in this region were positively correlated with word report scores, suggesting a functional role for this increased activity.

In summary, there is ample behavioral evidence that perceptual challenges caused by acoustic degradation or distortion can alter the neural processes required for spoken language comprehension. Although particularly relevant in the context of age-related hearing loss, these same principles also likely apply in the case of background noise (Scott \& McGettigan, 2013), 
competing talkers, or non-native accents (Van Engen \& Peelle, 2014). Thus, again, issues raised in the context of normal aging have broad implications for models of speech perception.

\section{Language production in normal aging}

\section{Syllable production}

Older adults experience more word-finding failures and more filled pauses (for example, saying "um") during speech production, along with overall slower rates of production (Duchin \& Mysak, 1987). These production challenges might be caused by difficulty with lexical retrieval, difficulty accessing the correct speech sounds (phonology) associated with a lexical item, or difficulty forming the appropriate motor plan. The fact that older adults take longer to make sequential speech movements and make more articulatory errors (Bilodeau-Mercure et al., 2015) is consistent with at least some age effect on motor planning or production.

Sörös and colleagues (2011) had young and older adults produce syllabic sounds (the vowel /a/ and the multisyllabic token/pataka/) in an fMRI study. They found significantly lower activity in older adults in bilateral temporal cortex (near primary and secondary auditory cortex), but significantly more activity in older adults in bilateral middle temporal gyrus and large portions of bilateral frontal cortex. Tremblay and Deschamps (2016) investigated the relationship of brain structure for young older adults producing sequences of syllables that were simple (e.g., /pa-pa-pa-pa-pa-pa/) or complex (e.g., /pa-ta-ka-pa-ta-ka/). Behaviorally, older adults took longer, and were less accurate, in their production compared to young adults. Individual differences in speech production behavior correlated with regions of temporal and frontal cortex that also showed age-related decreases in cortical thickness in the same participants. Together these findings suggest a link between age-related neuroanatomical change and concomitant alterations in speech production.

\section{Word retrieval and picture naming}

There is ample evidence that age-related differences in speech production go beyond motor planning. Speech production is frequently assessed in the context of object naming, which beyond visual object recognition requires retrieving the name of an object (lexical information) and its corresponding phonological form prior to producing it (Indefrey \& Levelt, 2004). During picture naming tasks, older adults often have more difficulty producing correct names for pictures than young adults, particularly for low-frequency items (Nicholas, Obler, Albert, \& Goodglass, 1985; Rogalski, Peelle, \& Reilly, 2011). Weirenga and colleagues (2008) used fMRI to examine neural activity during picture naming in young and older adults. Although there were no age differences in accuracy, older adults appeared to show increased activity in several regions of both temporal and frontal cortex, including right IFG and bilateral insula. Individual differences in activity in several of these regions showed positive correlations with accuracy.

Perhaps the most compelling evidence for age-related difficulties in word retrieval is found in the tip-of-the-tongue (TOT) experience, in which a speaker is certain they know a word but is unable to produce it (for example, what is the name of the strait between Alaska and Siberia?). Older adults experience TOT states significantly more often than young adults, and particularly frequently for proper nouns (Burke, MacKay, Worthley, \& Wade, 1991). Phonological (homophone) priming improves older adults' retrieval of proper names (Burke, Locantore, Austin, \& Chase, 2004), suggesting that difficulty retrieving phonological information my underlie these TOT states: that is, semantic and/or lexical information have been accessed (resulting in a strong feeling of knowing) but phonological retrieval has not yet occurred (preventing the word from being produced). 
In an effort to identify the neural systems involved in TOT states, Shafto and colleagues (2007) examined gray matter density and TOT occurrence in older adults, and found that increased TOTs were associated with reduced gray matter in the left insula and anterior cingulate cortex. These findings were anatomically dissociable from regions of gray matter that correlated with scores on an executive processing task (Ravens progressive matrices), suggesting that agerelated changes in TOTs are not simply reflecting an overall cognitive decline. Converging evidence from fMRI on a similar experiment also showed increased left anterior insula activity for TOT states (Shafto, Stamatakis, Tam, \& Tyler, 2010). (It is interesting to consider these structural findings in the anterior insula in the context of the error-related activity often reported in the cingulo-opercular network - it may be that TOTs are related to general states of attention and error-monitoring seen in the cases of perceptual errors.)

Aging is thus associated with differences in picture naming and word production. Although some of these differences may be due to changes in articulatory fluency or control, there is also evidence suggesting age-related changes to lexical or phonological retrieval stages of processing.

\section{Sentence and discourse production}

In comparison to single word production and naming, there has been little work on the cognitive neuroscience of sentence or discourse production in healthy aging. However, it is worth briefly noting that a number of striking age differences have been observed. A particularly interesting way of assessing sentence production is to examine diaries or other writing samples produced over time. In these cases, the complexity of written sentences has been found to decrease over time (Kemper, 1987; Kemper, Greiner, et al., 2001). This includes decreases in syntactic complexity and idea density. Provocatively, longitudinal studies have found that the linguistic complexity of writing samples in early life has been found to be predictive of developing Alzheimer's disease in older age (Snowdon et al., 1996). Measures of speech production in the context of storytelling can also help distinguish between patients with a variety of neurodegenerative diseases (Ash et al., 2014; Ash et al., 2006). Thus, connected speech offers a number of additional insights to language production that may not be available with word or picture naming.

\section{Aging and the effects of multilingualism on language processing and cognitive function}

Recent years have seen increasing interest in the effects of bilingualism (or more generally, multilingualism) on language and cognitive processing. Multilingualism presents a number of complex cognitive challenges. For example, storing multiple lexicons may provide extra linguistic support, but also requires choosing between a greater number of words referring to an intended concept. Code switching - that is, changing from one language to another in production (or comprehension) - also requires cognitive control and flexibility (Gollan \& Ferreira, 2009; Olson, 2017). Because of these added demands, multilingualism is frequently associated with inhibition and task-switching (Abutalebi \& Green, 2008; De Baene, Duyck, Brass, \& Carreiras, 2015; Green \& Abutalebi, 2013). Multilingualism is also associated with a number of neural changes, including functional processing changes in the caudate (Crinion et al., 2006), and structural changes in left frontal and parietal cortices (Grogan et al., 2012; Mechelli et al., 2004; Stein et al., 2012). Although some potential converging links may be observed between specific brain regions and cognitive processes implicated in multilingual processing, the correspondence is not always straightforward (Higby, Kim, \& Obler, 2013).

Given age-related changes in cognitive function it interesting to consider how multilingualism fits in to the aging process. In particular, an area of burgeoning interest is the 
degree to which bilingualism may lead to improved cognitive processing, especially in older age (Bak, Nissan, Allerhand, \& Deary, 2014; Bialystok, Craik, \& Luk, 2012; Kavé, Eyal, Shorek, \& Cohen-Mansfield, 2008). Early behavioral work suggested bilingualism was associated with altered executive processing (Bialystok, Craik, Klein, \& Viswanathan, 2004; Prior \& MacWhinney, 2009), a finding that has also found some support in brain imaging studies (Gold, Johnson, \& Powell, 2013; Gold, Kim, Johnson, Kryscio, \& Smith, 2013; Schweizer, Ware, Fischer, Craik, \& Bialystok, 2012). One compelling hypothesis is that years of multilingual processing results in cognitive changes, building cognitive reserve that can have a protective effect against age-related cognitive decline (Craik, Bialystok, \& Freedman, 2010). That being said, disagreement exists as to the extent to which bilingualism affects cognitive processing in older adults (Antón, García, Carreiras, \& Duñabeitia, 2016), and further data are likely needed to fully resolve the issue.

\section{Beyond individual brain regions: network balance during language processing}

Owing in part to the prominent role that language processing has played in the history of localizing brain function, it can be tempting to think about age-related changes in neural activity in terms of discrete regions being activated differently in older adults compared to young adults. Although there is some truth to be found from this perspective, a more accurate framework is likely one in which individual differences in sensory and cognitive ability lead to altered dynamics of interacting brain networks (Shafto \& Tyler, 2014). From this network-centered perspective, levels of activity in any given network arise naturally out of the balance between processing efficiency and task requirements illustrated in Figure 1. Individual differences in neurobiology, and concomitant sensory and cognitive ability, thus assume the primary explanatory position, rather than age per se. Operationally, a network-based perspective might be supported by analyses incorporating structural brain measures, functional brain measures, and behavior to investigate systematic variability across participants (Meunier, Stamatakis, \& Tyler, 2014). Recent studies that have taken network-based approaches to aging suggest age-related changes in network connectivity (Tsvetanov et al., 2016) that underlie older adults success with at least some language tasks (Campbell et al., 2016).

\section{Conclusions}

Adult aging is an ideal framework within which to study how individual differences in cognitive and perceptual factors influence language processing. Evidence from functional brain imaging suggests that age-related changes in the neural underpinnings of language processing are present at nearly every level of linguistic processing - syllables, words, sentences, and discourse - in both production and comprehension. Thus, although language processing is generally well preserved in older adulthood, this behavioral success is accomplished using a different balance of cognitive and neural processing in older adults. Emerging work specifically looking at individual differences in older adults' brain activity is an exciting new direction. It may well be that improved measures of neural integrity, sensory acuity, and cognitive ability ultimately prove more useful in predicting language processing than chronological age. 


\section{Acknowledgements}

This work was supported by grants R01DC14281 and R01AG038490 from the US National Institutes of Health.

\section{References}

Abutalebi, J., \& Green, D. W. (2008). Control mechanisms in bilingual language production: Neural evidence from language switching studies. Language and Cognitive Processes, $23,557-582$.

Antón, E., García, Y. F., Carreiras, M., \& Duñabeitia, J. A. (2016). Does bilingualism shape inhibitory control in the elderly? Journal of Memory and Language, 90, 147-160. doi: 10.1016/j.jml.2016.04.007

Ash, S., Menaged, A., Olm, C., McMillan, C. T., Boller, A., Irwin, D. J., . . Grossman, M. (2014). Narrative discourse deficits in amyotrophic lateral sclerosis. Neurology, 83, 520528.

Ash, S., Moore, P., Antani, S., McCawley, G., Work, M., \& Grossman, M. (2006). Trying to tell a tale: Discourse impairments in progressive aphasia and frontotemporal dementia. Neurology, 66, 1405-1413.

Bak, T. H., Nissan, J. J., Allerhand, M. M., \& Deary, I. J. (2014). Does bilingualism influence cognitive aging? Annals of Neurology, 75, 959-963. doi: 10.1002/ana.24158

Bialystok, E., Craik, F. I. M., Klein, R., \& Viswanathan, M. (2004). Bilingualism, aging, and cognitive control: Evidence from the Simon Task. Psychology and Aging, 19, 290-303. doi: 10.1037/0882-7974.19.2.290

Bialystok, E., Craik, F. I. M., \& Luk, G. (2012). Bilingualism: Consequences for mind and brain. Trends in Cognitive Sciences, 16, 240-250. doi: 10.1016/j.tics.2012.03.001

Bilodeau-Mercure, M., Kirouac, V., Langlois, N., Ouellet, C., Gasse, I., \& Tremblay, P. (2015). Movement sequencing in normal aging: Speech, oro-facial, and finger movements. Age, 37,78 .

Bilodeau-Mercure, M., Lortie, C. L., Sato, M., Guitton, M., \& Tremblay, P. (2015). The neurobiology of speech perception decline in aging. Brain Structure and Function, 220, 979-997.

Burke, D. M., Locantore, J., Austin, A., \& Chase, B. (2004). Cherry pit primes Brad Pitt: Homophone priming effects on young and older adults' production of proper names. Psychological Science, 15, 164-170.

Burke, D. M., MacKay, D. G., Worthley, J. S., \& Wade, E. (1991). On the tip of the tongue: What causes word finding failures in young and older adults? Journal of Memory and Language, 30, 542-579.

Cabeza, R. (2002). Hemispheric asymmetry reduction in older adults: The HAROLD model. Psychology and Aging, 17(1), 85-100.

Cabeza, R., Grady, C. L., Nyberg, L., McIntosh, A. R., Tulving, E., Kapur, S., . . Craik, F. I. M. (1997). Age-related differences in neural activity during memory encoding and retrieval: A positron emission tomography study. Journal of Neuroscience, 17, 391-400.

Campbell, K. L., Samu, D., Davis, S. W., Geerligs, L., Mustafa, A., Tyler, L. K., \& Cam-CAN. (2016). Robust resilience of the frontotemporal syntax system to aging. Journal of Neuroscience, 36, 5214-5227. 
Caplan, D., \& Waters, G. S. (1999). Verbal working memory and sentence comprehension. Behavioral and Brain Sciences, 22(1), 77-126.

Cousins, K. A. Q., Dar, H., Wingfield, A., \& Miller, P. (2014). Acoustic masking disrupts timedependent mechanisms of memory encoding in word-list recall. Memory and Cognition, 42, 622-638.

Craik, F. I. M., Bialystok, E., \& Freedman, M. (2010). Delaying the onset of Alzheimer disease: Bilingualism as a form of cognitive reserve. Neurology, 75, 1726-1729. doi: 10.1212/ WNL.0b013e3181fc2a1c

Crinion, J. T., Turner, R., Grogan, A., Hanakawa, T., Uppeney, U., Devlin, J. T., . . Price, C. J. (2006). Language control in teh bilingual brain. Science, 312, 1537-1540. doi: 10.1126/science.1127761

D'Esposito, M., Zarahn, E., Aguirre, G. K., \& Rypma, B. (1999). The effect of normal aging on the coupling of neural activity to the bold hemodynamic response. NeuroImage, 10(1), 614.

Davis, S. W., Zhuang, J., Wright, P., \& Tyler, L. K. (2014). Age-related sensitivity to taskrelated modulation of language-processing networks. Neuropsychologia, 63, 107-115.

De Baene, W., Duyck, W., Brass, M., \& Carreiras, M. (2015). Brain circuit for cognitive control is shared by task and language switching. Journal of Cognitive Neuroscience, 27, 17521765. doi: 10.1162/jocn_a_00817

Dosenbach, N. U. F., Fair, D. A., Cohen, A. L., Schlaggar, B. L., \& Petersen, S. E. (2008). A dual-networks architecture of top-down control. Trends in Cognitive Sciences, 12, 99105.

Dubno, J. R., Ahlstrom, J. B., \& Horwitz, A. R. (2000). Use of context by young and aged adults with normal hearing. Journal of the Acoustical Society of America, 107, 538-546.

Dubno, J. R., Dirks, D. D., \& Morgan, D. E. (1984). Effects of age and mild hearing loss on speech recognition in noise. Journal of the Acoustical Society of America, 76(1), 87-96.

Duchin, S. W., \& Mysak, E. D. (1987). Disfluency and rate characteristics of young adult, middle-aged, and older males. Journal of Communication Disorders, 20, 245-257.

Duncan, J. (2010). The multiple-demand (MD) system of the primate brain: mental programs for intelligent behaviour. Trends in Cognitive Sciences, 14, 172-179.

Eckert, M. A., Menon, V., Walczak, A., Ahlstrom, J., Denslow, S., Horwitz, A., \& Dubno, J. R. (2009). At the heart of the ventral attention system: The right anterior insula. Human Brain Mapping, 30, 2530-2541.

Eckert, M. A., Walczak, A., Ahlstrom, J., Denslow, S., Horwitz, A., \& Dubno, J. R. (2008). Agerelated effects on word recognition: Reliance on cognitive control systems with structural declines in speech-responsive cortex. Journal of the Association for Research in Otolaryngology, 9, 252-259.

Erb, J., \& Obleser, J. (2013). Upregulation of cognitive control networks in older adults' speech comprehension. Frontiers in Systems Neuroscience, 7, 116.

Federmeier, K. D., \& Kutas, M. (2005). Aging in context: Age-related changes in context use during language comprehension. Psychophysiology, 42, 133-141.

Federmeier, K. D., Kutas, M., \& Schul, R. (2010). Age-related and individual differences in the use of prediction during language comprehension. Brain and Language, 115, 149-161.

Fjell, A. M., Walhovd, K. B., Fennema-Notestine, C., McEvoy, L. K., Hagler, D. J., Holland, D., ... Dale, A. M. (2009). One-year brain atrophy evident in healthy aging. Journal of Neuroscience, 29, 15223-15231.

Fodor, J. A. (1983). The modularity of mind. Cambridge, MA: MIT Press. 
Gagnepain, P., Henson, R. N., \& Davis, M. H. (2012). Temporal predictive codes for spoken words in auditory cortex. Current Biology, 22, 615-621.

Gold, B. T., Johnson, N. F., \& Powell, D. K. (2013). Lifelong bilingualism contributes to cognitive reserve against white matter integrity declines in aging. Neuropsychologia, 51, 2841-2846. doi: 10.1016/j.neuropsychologia.2013.09.037

Gold, B. T., Kim, C., Johnson, N. F., Kryscio, R. J., \& Smith, C. D. (2013). Lifelong bilingualism maintains neural efficiency for cognitive control in aging. Journal of Neuroscience, 33, 387-396. doi: 10.1523/JNEUROSCI.3837-12.2013

Gollan, T. H., \& Ferreira, V. S. (2009). Should I stay or should I switch? A cost-benefit analysis of voluntary language switching in young and aging bilinguals. Journal of Experimental Psychology: Learning, Memory, and Cognition, 35, 640-665. doi: 10.1037/a0014981

Good, C. D., Johnsrude, I. S., Ashburner, J., Henson, R. N. A., Friston, K. J., \& Frackowiak, R. S. J. (2001). A voxel-based morphometric study of ageing in 465 normal adult human brains. NeuroImage, 14, 21-36.

Grady, C. L. (2000). Functional brain imaging and age-related changes in cognition. Biological Psychology, 54, 259-281.

Green, D. W., \& Abutalebi, J. (2013). Language control in bilinguals: The adaptive control hypothesis. Journal of Cognitive Psychology, 25(5), 515-530. doi: 10.1080/20445911.2013.796377

Grogan, A., Parker Jones, O., Ali, N., Crinion, J., Orabona, S., Mechias, M. L., . . Price, C. J. (2012). Structural correlates for lexical efficiency and number of languages in non-native speakers of English. Neuropsychologia, 50, 1347-1352. doi: 10.1016/j.neuropsychologia.2012.02.019

Hasher, L., Stoltzfus, E. R., Zacks, R. T., \& Rypma, B. (1991). Age and inhibition. Journal of Experimental Psychology: Learning, Memory, and Cognition, 17(1), 163-169.

Hedden, T., \& Gabrieli, J. D. E. (2004). Insights into the ageing mind: A view from cognitive neuroscience. Nature Reviews Neuroscience, 5, 87-96.

Hickok, G., \& Poeppel, D. (2007). The cortical organization of speech processing. Nature Reviews Neuroscience, 8, 393-402.

Higby, E., Kim, J., \& Obler, L. K. (2013). Multilingualism and the brain. Annual Review of Applied Linguistics, 33, 68-101. doi: 10.1017/S0267190513000081

Humes, L. E., Kewley-Port, D., Fogerty, D., \& Kinney, D. (2010). Measures of hearing threshold and temporal processing across the adult lifespan. Hearing Research, 264, 30-40.

Humes, L. E., Kidd, G. R., \& Lentz, J. J. (2013). Auditory and cognitive factors underlying individual differences in aided speech-understanding among older adults. Frontiers in Systems Neuroscience, 7, 55.

Indefrey, P., \& Levelt, W. J. M. (2004). The spatial and temporal signatures of word production components. Cognition, 92, 101-144. doi: 10.1016/j.cognition.2002.06.001

Jones, D. K., Knösche, T. R., \& Turner, R. (2013). White matter integrity, fiber count, and other fallacies: The do's and don'ts of diffusion MRI. NeuroImage, 73, 239-254.

Kavé, G., Eyal, N., Shorek, A., \& Cohen-Mansfield, J. (2008). Multilingualism and cognitive state in the oldest old. Psychology and Aging, 23, 70-78. doi: 10.1037/0882-7974.23.1.70

Kemper, S. (1987). Life span changes in syntactic complexity. Journal of Gerontology, 42, 323328.

Kemper, S. (1992). Language and aging. In F. I. M. Craik \& T. A. Salthouse (Eds.), The handbook of aging and cognition (pp. 213-270). Hillsdale, NJ: Lawrence Erlbaum Associates. 
Kemper, S., Greiner, L. H., Marquis, J. G., Prenovost, K., \& Mitzner, T. L. (2001). Language decline across the life span: findings from the Nun Study. Psychology and Aging, 16(2), 227-239.

Kemper, S., Marquis, J., \& Thompson, M. (2001). Longitudinal change in language production: effects of aging and dementia on grammatical complexity and propositional content. Psychology and Aging, 16(4), 600-614.

Kemtes, K. A., \& Kemper, S. (1997). Younger and older adults' on-line processing of syntactically ambiguous sentences. Psychology and Aging, 12(2), 362-371.

Kuchinsky, S. E., Vaden Jr., K. I., Keren, N. I., Harris, K. C., Ahlstrom, J. B., Dubno, J. R., \& Eckert, M. A. (2012). Word intelligibility and age predict visual cortex activity during word listening. Cerebral Cortex, 22, 1360-1371.

Kutas, M., \& Hillyard, S. A. (1984). Brain potentials during reading reflect word expectancy and semantic association. Nature, 307, 161-163.

Lash, A., Rogers, C. S., Zoller, A., \& Wingfield, A. (2013). Expectation and entropy in spoken word recognition: Effects of age and hearing acuity. Experimental Aging Research, 39, 235-253.

Luce, P. A., \& Pisoni, D. B. (1998). Recognizing spoken words: The neighborhood activation model. Ear and Hearing, 19, 1-36.

Marslen-Wilson, W. D. (1987). Functional parallelism in spoken word recognition. Cognition, 25, 71-102.

Marslen-Wilson, W. D., \& Tyler, L. K. (1980). The temporal structure of spoken language processing. Cognition, 8, 1-71.

McCoy, S. L., Tun, P. A., Cox, L. C., Colangelo, M., Stewart, R., \& Wingfield, A. (2005). Hearing loss and perceptual effort: Downstream effects on older adults' memory for speech. Quarterly Journal of Experimental Psychology, 58(1), 22-33.

Mechelli, A., Crinion, J. T., Noppeney, U., O'Doherty, J., Ashburner, J., Frackowiak, R. S., \& Price, C. J. (2004). Structural plasticity in the bilingual brain. Nature, 431, 757.

Meunier, D., Stamatakis, E. A., \& Tyler, L. K. (2014). Age-related functional reorganization, structural changes, and preserved cognition. Neurobiology of Aging, 35, 42-54.

Miller, P., \& Wingfield, A. (2010). Distinct effects of perceptual quality on auditory word recognition, memory formation and recall in a neural model of sequential memory. Frontiers in Systems Neuroscience, 4, 14.

Mitchell, K. J., Johnson, M. K., Raye, C. L., Mather, M., \& D'Esposito, M. (2000). Aging and reflective processes of working memory: Binding and test load deficits. Psychology and Aging, 15, 527-541.

Morrell, C. H., Gordon-Salant, S., Pearson, J. D., Brant, L. J., \& Fozard, J. L. (1996). Age- and gender-specific reference ranges for hearing level and longitudinal changes in hearing level. Journal of the Acoustical Society of America, 100(4, Pt 1), 1949-1967.

Neta, M., Miezin, F. M., Nelson, S. M., Dubis, J. W., Dosenbach, N. U. F., Schlaggar, B. L., \& Petersen, S. E. (2015). Spatial and temporal characteristics of error-related activity in the human brain. Journal of Neuroscience, 35, 253-266.

Nicholas, M., Obler, L., Albert, M., \& Goodglass, H. (1985). Lexical retrieval in healthy aging. Cortex, 21, 595-606.

Norris, D., \& McQueen, J. M. (2008). Shortlist B: A Bayesian model of continuous speech recognition. Psychological Review, 115, 357-395.

Olson, D. J. (2017). Bilingual language switching costs in auditory comprehension. Language, Cognition and Neuroscience, 32, 494-513. doi: 10.1080/23273798.2016.1250927 
Park, D. C., Polk, T. A., Park, R., Minear, M., Savage, A., \& Smith, M. R. (2004). Aging reduces neural specialization in ventral visual cortex. Proceedings of the National Academy of Sciences, 101(35), 13091-13095.

Peelle, J. E. (2012). The hemispheric lateralization of speech processing depends on what "speech" is: A hierarchical perspective. Frontiers in Human Neuroscience, 6, 309.

Peelle, J. E., Cusack, R., \& Henson, R. N. A. (2012). Adjusting for global effects in voxel-based morphometry: Gray matter decline in normal aging. NeuroImage, 60, 1503-1516.

Peelle, J. E., Johnsrude, I. S., \& Davis, M. H. (2010). Hierarchical processing for speech in human auditory cortex and beyond. Frontiers in Human Neuroscience, 4, 51. doi: doi:10.3389/fnhum.2010.00051

Peelle, J. E., Troiani, V., Wingfield, A., \& Grossman, M. (2010). Neural processing during older adults' comprehension of spoken sentences: Age differences in resource allocation and connectivity. Cerebral Cortex, 20, 773-782.

Peelle, J. E., \& Wingfield, A. (2016). The neural consequences of age-related hearing loss. Trends in Neurosciences, 39, 486-497. doi: 10.1016/j.tins.2016.05.001

Pichora-Fuller, M. K., Kramer, S. E., Eckert, M. A., Edwards, B., Hornsby, B. W. Y., Humes, L. E., ... Wingfield, A. (2016). Hearing impairment and cognitive energy: The framework for understanding effortful listening (FUEL). Ear and Hearing, 37, 5S-27S.

Pichora-Fuller, M. K., Schneider, B. A., \& Daneman, M. (1995). How young and old adults listen to and remember speech in noise. Journal of the Acoustical Society of America, 97(1), 593-608.

Piquado, T., Cousins, K. A. Q., Wingfield, A., \& Miller, P. (2010). Effects of degraded sensory input on memory for speech: Behavioral data and a test of biologically constrained computational models. Brain Research Bulletin, 1365, 48-65.

Power, J. D., Barnes, K. A., Snyder, A. Z., Schlaggar, B. L., \& Petersen, S. E. (2012). Spurious but systematic correlations in functional connectivity MRI networks arise from subject motion. NeuroImage, 59, 2142-2154.

Power, J. D., \& Petersen, S. E. (2013). Control-related systems in the human brain. Current Opinion in Neurobiology, 23, 223-228.

Prior, A., \& MacWhinney, B. (2009). A bilingual advantage in task switching. Bilingualism: Language and Cognition, 13, 253-262. doi: 10.1017/S1366728909990526

Rabbitt, P. M. A. (1968). Channel capacity, intelligibility and immediate memory. Quarterly Journal of Experimental Psychology, 20, 241-248.

Rabbitt, P. M. A. (1991). Mild hearing loss can cause apparent memory failures which increase with age and reduce with IQ. Acta Otolaryngolica, 476, 167-176.

Rauschecker, J. P., \& Scott, S. K. (2009). Maps and streams in the auditory cortex: nonhuman primates illuminate human speech processing. Nature Neuroscience, 12, 718-724.

Raz, N., Gunning, F. M., Head, D., Dupuis, J. H., McQuain, J., Briggs, S. D., . . Acker, J. D. (1997). Selective aging of the human cerebral cortex observed in vivo: Differential vulnerability of the prefrontal gray matter. Cerebral Cortex, 7, 268-282.

Raz, N., Gunning-Dixon, F. M., Head, D., Dupuis, J. H., \& Acker, J. D. (1998). Neuroanatomical correlates of cognitive aging: Evidence from structural magnetic resonance imaging. Neuropsychology, 12(1), 95-114.

Raz, N., Lindenberger, U., Rodrigue, K. M., Kennedy, K. M., Head, D., Williamson, A., .. . Acker, J. D. (2005). Regional brain changes in aging healthy adults: General trends, individual differences and modifiers. Cerebral Cortex, 15, 1676-1689.

Reuter-Lorenz, P. A., \& Lustig, C. (2005). Brain aging: reorganizing discoveries about the aging mind. Current Opinion in Neurobiology, 15, 245-251. 
Reuter-Lorenz, P. A., \& Park, D. C. (2014). How does it STAC up? Revisiting the scaffolding theory of aging and cognition. Neuropsychology Review, 24, 355-370.

Rodd, J. M., Johnsrude, I. S., \& Davis, M. H. (2012). Dissociating frontotemporal contributions to semantic ambiguity resolution in spoken sentences. Cerebral Cortex, 22, 1761-1773.

Rogalski, Y., Peelle, J. E., \& Reilly, J. (2011). Effects of perceptual and contextual enrichment on visual confrontation naming in aging. Journal of Speech, Language, and Hearing Research, 54, 1349-1360.

Rönnberg, J., Lunner, T., Zekveld, A., Sörqvist, P., Danielsson, H., Lyxell, B., . . Rudner, M. (2013). The ease of language understanding (ELU) model: theoretical, empirical, and clinical advances. Frontiers in Systems Neuroscience, 7, 31.

Salat, D. H., Buckner, R. L., Snyder, A. Z., Greve, D. N., Desikan, R. S. R., Busa, E., .. . Fischl, B. (2004). Thinning of the cerebral cortex in aging. Cerebral Cortex, 14, 721-730.

Salat, D. H., Lee, S. Y., van der Kouwe, A. J., Greve, D. N., Fischl, B., \& Rosas, H. D. (2009). Age-associated alterations in cortical gray and white matter signal intensity and gray to white matter contrast. NeuroImage, 48, 21-28.

Salat, D. H., Tuch, D. S., Greve, D. N., van der Kouwe, A. J. W., Hevelone, N. D., Zaleta, A. K., ... Dale, A. M. (2005). Age-related alterations in white matter microstructure measured by diffusion tensor imaging. Neurobiology of Aging, 26, 1215-1227.

Salthouse, T. A. (1996). The processing-speed theory of adult age differences in cognition. Psychological Review, 103(3), 403-428.

Schneider, B. A. (1997). Psychoacoustics and aging: Implications for everyday listening. Journal of Speech-Language Pathology and Audiology, 21(2), 111-124.

Schweizer, T. A., Ware, J., Fischer, C. E., Craik, F. I. M., \& Bialystok, E. (2012). Bilingualism as a contributor to cognitive reserve: Evidence from brain atrophy in Alzheimer's disease. Cortex, 48, 991-996. doi: 10.1016/j.cortex.2011.04.009

Scott, S. K., \& McGettigan, C. (2013). The neural processing of masked speech. Hearing Research, 303, 58-66.

Shafto, M. A., Burke, D. M., Stamatakis, E. A., Tam, P. P., \& Tyler, L. K. (2007). On the tip-ofthe-tongue: Neural correlates of increased word-finding failures in normal aging. Journal of Cognitive Neuroscience, 19(12).

Shafto, M. A., Randall, B., Stamatakis, E. A., Wright, P., \& Tyler, L. K. (2012). Age-related neural reorganization during spoken word recognition: The interaction of form and meaning. Journal of Cognitive Neuroscience, 24, 1434-1446.

Shafto, M. A., Stamatakis, E. A., Tam, P. P., \& Tyler, L. K. (2010). Word retrieval failures in old age: The relationship between structure and function. Journal of Cognitive Neuroscience, $22,1530-1540$.

Shafto, M. A., \& Tyler, L. K. (2014). Language in the aging brain: The network dynamics of decline and preservation. Science, 346, 583-587.

Shannon, R. V., Zeng, F.-G., Kamath, V., Wygonski, J., \& Ekelid, M. (1995). Speech recognition with primarily temporal cues. Science, 270, 303-304.

Snowdon, D. A., Kemper, S. J., Mortimer, J. A., Greiner, L. H., Wekstein, D. R., \& Markesbery, W. R. (1996). Linguistic ability in early life and cognitive function and Alzheimer's disease in late life: Findings from the Nun Study. Journal of the American Medical Association, 275, 528-532.

Sommers, M. S. (1996). The structural organization of the mental lexicon and its contribution to age-related declines in spoken-word recognition. Psychology and Aging, 11(2), 333-341. 
Sommers, M. S., \& Danielson, S. M. (1999). Inhibitory processes and spoken word recognition in young and older adults: The interaction of lexical competition and semantic context. Psychology and Aging, 14, 458-472.

Sörös, P., Bose, A., Sokoloff, L. G., Graham, S. J., \& Stuss, D. T. (2011). Age-related changes in the functional neuroanatomy of overt speech production. Neurobiology of Aging, 32, 1505-1513.

Stein, M., Federspiel, A., Koenig, T., Wirth, M., Strik, W., Wiest, R., .. . Dierks, T. (2012). Structural plasticity in the language system related to increased second language proficiency. Cortex, 48, 458-465. doi: 10.1016/j.cortex.2010.10.007

Stokes, M. G., Kusunoki, M., Sigala, N., Nili, H., Gaffan, D., \& Duncan, J. (2013). Dynamic coding for cognitive control in prefrontal cortex. Neuron, 78, 364-375.

Tremblay, P., \& Deschamps, I. (2016). Structural brain aging and speech production: A surfacebased brain morphometry study. Brain Structure and Function, 221, 3275-3299.

Tsvetanov, K. A., Henson, R. N. A., Tyler, L. K., Davis, S. W., Shafto, M. A., Taylor, J. R., .. . Rowe, J. B. (2015). The effect of ageing on fMRI: Correction for the confounding effects of vascular reactivity evaluated by joint fMRI and MEG in 335 adults. Human Brain Mapping, 36, 2248-2269.

Tsvetanov, K. A., Henson, R. N. A., Tyler, L. K., Razi, A., Geerligs, L., Ham, T. E., . . CamCAN. (2016). Extrinsic and intrinsic brain network connectivity maintains cognition across the lifespan despite accelerated decay of regional brain activation. Journal of Neuroscience, 36, 3115-3126. doi: 10.1523/JNEUROSCI.2733-15.2016

Tyler, L. K., Shafto, M. A., Randall, B., Wright, P., Marslen-Wilson, W. D., \& Stamatakis, E. A. (2010). Preserving syntactic processing across the adult life span: The modulation of the frontotemporal language system in the context of age-related atrophy. Cerebral Cortex, 20, 352-364.

Vaden Jr., K. I., Kuchinsky, S. E., Ahlstrom, J. B., Dubno, J. R., \& Eckert, M. A. (2015). Cortical activity predicts which older adults recognize speech in noise and when. Journal of Neuroscience, 35, 3929-3937.

Vaden Jr., K. I., Kuchinsky, S. E., Cute, S. L., Ahlstrom, J. B., Dubno, J. R., \& Eckert, M. A. (2013). The cingulo-opercular network provides word-recognition benefit. Journal of Neuroscience, 33, 18979-18986.

Van Engen, K. J., \& Peelle, J. E. (2014). Listening effort and accented speech. Frontiers in Human Neuroscience, 8, 577.

Verhaeghen, P. (2003). Aging and vocabulary score: A meta-analysis. Psychology and Aging, 18(2), 332-339.

Ward, C. M., Rogers, C. S., Van Engen, K. J., \& Peelle, J. E. (2016). Effects of age, acoustic challenge, and verbal working memory on recall of narrative speech. Experimental Aging Research, 42, 126-144.

Waters, G. S., \& Caplan, D. (2001). Age, working memory, and on-line syntactic processing in sentence comprehension. Psychology and Aging, 16(1), 128-144.

Whiting, W. L., Madden, D. J., Langley, L. K., Denny, L. L., Turkington, T. G., Provenzale, J. M., . . . Coleman, R. E. (2003). Lexical and sublexical components of age-related changes in neural activation during visual word identification. Journal of Cognitive Neuroscience, 15, 475-487.

Wierenga, C. E., Benjamin, M., Gopinath, K., Perlstein, W. M., Leonard, C. M., Gonzalez Rothi, L. J., . . Crosson, B. (2008). Age-related changes in word retrieval: Role of bilateral frontal and subcortical networks. Neurobiology of Aging, 29, 436-451. 
Wingfield, A., Aberdeen, J. S., \& Stine, E. A. (1991). Word onset gating and linguistic context in spoken word recognition by young and elderly adults. Journals of Gerontology, 46(3), 127-129.

Wingfield, A., \& Grossman, M. (2006). Language and the aging brain: Patterns of neural compensation revealed by functional brain imaging. Journal of Neurophysiology, 96, 2830-2839.

Wingfield, A., Peelle, J. E., \& Grossman, M. (2003). Speech rate and syntactic complexity as multiplicative factors in speech comprehension by young and older adults. Aging, Neuropsychology, and Cognition, 10(4), 310-322.

Wingfield, A., \& Stine-Morrow, E. A. L. (2000). Language and speech. In F. I. M. Craik \& T. A. Salthouse (Eds.), The handbook of aging and cognition (2nd ed) (pp. 359-416). Mahwah, NJ: Lawrence Erlbaum Associates.

Wingfield, A., Tun, P. A., \& McCoy, S. L. (2005). Hearing loss in older adulthood: What it is and how it interacts with cognitive performance. Current Directions in Psychological Science, 14, 144-148.

Wlotko, E. W., Federmeier, K. D., \& Kutas, M. (2012). To predict or not to predict: Age-related differences in the use of sentential context. Psychology and Aging, 27, 975-988.

Woolgar, A., Hampshire, A., Thompson, R., \& Duncan, J. (2011). Adaptive coding of taskrelevant information in human frontoparietal cortex. Journal of Neuroscience, 31, 1459214599.

Zhuang, J., Tyler, L. K., Randall, B., Stamatakis, E. A., \& Marslen-Wilson, W. D. (2014). Optimially efficient neural systems for processing spoken language. Cerebral Cortex, 24, 908-918. 